\title{
Control of fatigue failure mechanisms in multilayer coatings by varying the architectural parameters of an intermetallic interlayer
}

\author{
Songsong $\mathrm{Lu}^{1}$, Richard $\mathrm{Cook}^{1}$, Yi Zhang ${ }^{2}$, and Philippa Reed ${ }^{1}$ \\ ${ }^{1}$ University of Southampton Faculty of Physical Sciences and Engineering \\ ${ }^{2}$ Daido Metal Co Ltd European Technical Centre (UK) Winterhay Lane Ilminister TA19 \\ 9PH UK
}

December 12, 2021

\begin{abstract}
A multilayer overlay coating system containing an intermediate intermetallic layer (designated 2IML) is an architecture expected to show good fatigue resistance. Experimental characterisation and modelling simulations were carried out to classify the different crack initiation mechanisms occurring during fatigue of this coating system and to reveal how changes in the layer architecture lead to fatigue improvement. Fatigue improvement is achieved by decreasing the IML-Top layer thickness due to the increased surface crack initiation resistance. However subsurface initiation mechanisms inhibit the improvement (dominated by surface initiation mechanism) achieved by locating the IML-Top layer closer to the top surface.
\end{abstract}

\section{Hosted file}

mymanuscript.docx available at https://authorea.com/users/450769/articles/549053-controlof-fatigue-failure-mechanisms-in-multilayer-coatings-by-varying-the-architecturalparameters-of-an-intermetallic-interlayer 